\title{
Effects of Pregnancy, Hypertension and Nitric Oxide Inhibition on Rat Uterine Artery Myogenic Reactivity
}

\author{
Carolyn Barron $^{a}$ Maurizio Mandala ${ }^{b}$ George Osol $^{a}$ \\ a Department of Obstetrics, Gynecology, and Reproductive Sciences, University of Vermont College of Medicine, \\ Burlington, Vt., USA; ${ }^{b}$ Department of Cell Biology, University of Calabria, Cozenza, Italy
}

\section{Key Words}

Uterus $\cdot$ Pressure-induced tone $\cdot$ Nitric oxide $\cdot$ L-NAME .

Hydralazine

\begin{abstract}
Background/Aims: The purpose of this study was to examine the effects of hypertension and nitric oxide (NO) inhibition on myogenic tone in uterine arteries during pregnancy. Methods: Premyometrial radial uterine arteries from nonpregnant and late pregnant Sprague-Dawley rats were evaluated for myogenic reactivity from the following groups: control, hypertensive/NO-inhibited (L-NAME treatment) and normotensive/NO-inhibited (L-NAME plus hydralazine). $\boldsymbol{R e}$ sults: In both nonpregnant and pregnant animals, L-NAME treatment significantly elevated blood pressures, while the addition of hydralazine made the animals normotensive. In nonpregnant animals, little myogenic tone was seen in controls; tone increased significantly in the L-NAME group, and was attenuated in those treated with L-NAME plus hydralazine. In pregnant animals, controls developed significant tone; this was reduced in the L-NAME group, and returned to control levels in the L-NAME plus hydralazine group. Conclusions: Dimensional measurements showed that arteries from the pregnant hypertensive group did not undergo expansive remodeling, suggesting that tone development is related to phenotypic alterations in vascular smooth muscle
\end{abstract}

and/or altered physical forces secondary to adaptive changes in arterial diameter. These differences implicate pregnancy-specific pathways in the development and inhibition of myogenic tone, and point to potentially opposing roles of $\mathrm{NO}$ and hypertension.

Copyright $\odot 2010$ S. Karger AG, Basel

\section{Introduction}

Hypertensive disorders of pregnancy, which include preeclampsia, are associated with decreased uterine blood flow and growth-restricted fetuses [1-3]. A significant cause of maternal as well as fetal morbidity and mortality, these disorders continue to account for $15-20 \%$ of maternal deaths worldwide [2-4]. Preeclampsia, defined by hypertension and proteinuria, further amplifies maternal and fetal risks, including intrauterine growth restriction, preterm labor and fetal death [2]. Furthermore, pregnancy-induced hypertension and/or preeclampsia puts women at greater risk of developing these disorders in future pregnancies and increases the likelihood of cardiovascular diseases (hypertension, stroke) occurring later in life [1, 5-7].

Under normal circumstances, the uterine vasculature undergoes dramatic remodeling in order to accommodate the requisite $>10$-fold increase in uterine blood flow

\section{KARGER}

(C) 2010 S. Karger AG, Basel

Fax +41613061234

E-Mail karger@karger.ch

www.karger.com
Accessible online at: www.karger.com/jvr
Dr. George Osol

Department of Obstetrics, Gynecology, and Reproductive Medicine

University of Vermont College of Medicine

C-217A Given Building, Burlington, VT 05405 (USA)

Tel. +1 802656 1203, Fax +1 802656 8771, E-Mail gosol@uvm.edu 
$[1,8,9]$ that allows for successful pregnancy outcome. In uterine vessels, outward expansive remodeling is seen (increased lumen diameter and unchanged wall thickness) $[10,11]$, which serves to reduce uterine vascular resistance in normal pregnancy $[4,12]$. Conversely, in chronic hypertensive states, this process is reversed, with inward remodeling (decreased lumen diameter and increased wall thickness) $[12,13]$ leading to a marked increase in peripheral vascular resistance $[3,9]$. In preeclamptic women, the interaction between gestation and hypertension results in an attenuated outward remodeling process [11], and placental underperfusion and endothelial dysfunction [14].

While structural gestational remodeling is a key factor in allowing for adequate increases in uterine blood flow, under physiological conditions, vascular resistance is determined by the combination of passive resistance artery structure and the ambient level of constriction, or tone. Myogenic tone - the intrinsic ability of smooth muscle to sustain constriction in response to intravascular pressure - is absent in uterine radial arteries from nonpregnant animals, yet appears in those same types of arteries in late pregnancy [15-17].

The objective of this study was to evaluate the effects of hypertension and nitric oxide (NO) inhibition on myogenic tone in pregnancy, as the ability of a vessel to constrict and dilate in response to changes in pressure plays a key role in regulating blood flow to the uterus. Our working hypothesis was that the level of tone would be directly related to hypertension and that treatment with L-NAME would cause increases in tone while co-treatment with hydralazine would cause a return to control levels of tone in both nonpregnant and late pregnant groups. Hydralazine was co-administered with L-NAME to normalize blood pressure and thereby dissociate the effects of elevated pressure from those of NO inhibition, as hydralazine is a widely used treatment for hypertension in pregnancy $[2,18,19]$. The results support this hypothesis in the nonpregnant state. During pregnancy, however, the data suggest that changes in tone may be primarily related to the degree of expansive remodeling, which appears to be mediated by both $\mathrm{NO}$ and intravascular pressure.

\section{Methods}

Animals, Experimental Treatments and Preparation of

Tissues

Adult (13-14-week-old) timed-pregnant female $(\mathrm{n}=53)$ and virgin nonpregnant $(n=29)$ Sprague-Dawley rats were purchased from Charles River Laboratories (St. Constant, Que., Canada) and housed in the Small Animal Facility at the University of Vermont which is fully accredited by the Association for Assessment and Accreditation of Laboratory Animal Care. Feed and water were provided ad libitum. All experimental protocols were approved by the Institutional Animal Care and Use Committee.

Six treatment groups were used: (1) nonpregnant controls, NP$\mathrm{C}, \mathrm{n}=12$; (2) nonpregnant hypertensives, $0.5 \mathrm{~g} / \mathrm{l}$ of L-NAME in drinking water, NP-L, $\mathrm{n}=11$; (3) nonpregnant NO-inhibited normotensives, $0.5 \mathrm{~g} / \mathrm{l} \mathrm{L}-\mathrm{NAME}$ plus $0.27 \mathrm{~g} / \mathrm{l}$ hydralazine in drinking water, NP-L $+\mathrm{H}, \mathrm{n}=6$; (4) late pregnant (day 20 of a 22-day gestation) controls, LP-C, $\mathrm{n}=23$; (5) late pregnant hypertensives, $\mathrm{L}-$ NAME in drinking water, as above, LP-L, $n=16$; (6) late pregnant NO-inhibited normotensives, treated with L-NAME and hydralazine as above, $\mathrm{LP}-\mathrm{L}+\mathrm{H}, \mathrm{n}=14$. In pregnant animals, treatment was started on days 9-10 of pregnancy, and continued until day 20; age-matched NP animals were also treated for a 10-day duration prior to experimentation.

Blood pressures were measured noninvasively by determining the tail blood volume with a volume-pressure recording sensor and an occlusion tail cuff (CODA System, Kent Scientific, Torrington, Conn., USA). Pressures were taken at the same time of day (late morning) 3 times during the course of the 10-day treatment. Mean arterial pressures (diastolic + one third of pulse pressure) were derived, and are expressed in $\mathrm{mm} \mathrm{Hg}$.

On the morning of an experiment, each animal was euthanized with an intraperitoneal injection of Nembutal (pentobarbital sodium, $50 \mathrm{mg} / \mathrm{kg}$; Ovation Pharmaceuticals, Deerfield, Ill., USA) and, once a surgical plane of anesthesia was attained, decapitated in a small animal guillotine. The abdomen was opened and the uterus and its contents removed and pinned in a Sylgardlined Petri dish filled with room temperature oxygenated (aerated with a mixture of $5 \% \mathrm{CO}_{2}, 10 \% \mathrm{O}_{2}$ and $85 \% \mathrm{~N}_{2}$ ) physiologic saline solution (PSS).

\section{Experimental Protocol}

All experiments utilized premyometrial as opposed to preplacental radial arteries to allow for direct comparisons from the nonpregnant to late pregnant state and to ensure maintained contractility, as preplacental radial vessels have been shown to lose contractility secondary to endovascular trophoblast invasion [16]. Once isolated and dissected clean of connective tissue, each vessel was cannulated in the chamber of an arteriograph (Instrumentation and Model Facility, University of Vermont, Burlington, Vt., USA), pressurized with a pressure-servo system (Living Systems Instrumentation, Burlington, Vt., USA) and positioned on the stage of an inverted microscope (Zeiss, Jena, Germany) equipped with a video camera as described previously [20, 21]. Vessels were superfused with PSS at a rate of $3 \mathrm{ml} / \mathrm{min}$ at $37^{\circ} \mathrm{C}$ and a $\mathrm{pH}$ of 7.4 (monitored in the bath near the vessel with a micro $\mathrm{pH}$ probe; Microelectrodes Inc., Bedford, N.H., USA). After cannulation, vessels were equilibrated for $40 \mathrm{~min}$ at $10 \mathrm{~mm}$ $\mathrm{Hg}, 20 \mathrm{~min}$ at $60 \mathrm{~mm} \mathrm{Hg}$, and then incubated with $0.2 \mathrm{~mm} \mathrm{N \omega}$ nitro-L-arginine (L-NNA) and $10 \mu \mathrm{M}$ indomethacin for $20 \mathrm{~min}$ at $60 \mathrm{~mm} \mathrm{Hg}$, to block any vasodilatory effects of $\mathrm{NO}$ and prostaglandins, respectively. Most often, the development of tone was seen during equilibration at $60 \mathrm{~mm} \mathrm{Hg}$ before incubation with blockers. If tone was not seen after equilibration, pressure was cycled $(10-60-100 \mathrm{~mm} \mathrm{Hg})$ to stretch the vessel and activate the myogenic response. Pressure was then lowered to $20 \mathrm{~mm} \mathrm{Hg}$ 
Table 1. Maternal and fetal characteristics of all treatment groups

\begin{tabular}{|c|c|c|c|c|c|c|}
\hline \multirow[t]{2}{*}{ Treatment group } & \multicolumn{2}{|c|}{ Maternal characteristics } & \multicolumn{4}{|c|}{ Fetal characteristics } \\
\hline & $\begin{array}{l}\text { maternal } \\
\text { weight, g }\end{array}$ & $\mathrm{MAP}^{1}, \mathrm{~mm} \mathrm{Hg}$ & litter size, \# & resorptions, \% & fetal weight, $g$ & $\begin{array}{l}\text { placental } \\
\text { weight, g }\end{array}$ \\
\hline NP control & $\begin{array}{l}302 \pm 4.1^{\mathrm{a}, \mathrm{b}} \\
(\mathrm{n}=12)\end{array}$ & $\begin{array}{l}103 \pm 1.6^{a, b} \\
(n=10)\end{array}$ & - & - & - & - \\
\hline NP L-NAME & $\begin{array}{l}285 \pm 5.0^{\mathrm{a}} \\
(\mathrm{n}=11)\end{array}$ & $\begin{array}{l}132 \pm 4.0^{c} \\
(\mathrm{n}=7)\end{array}$ & - & - & - & - \\
\hline $\begin{array}{l}\text { NP L-NAME + } \\
\text { hydralazine }\end{array}$ & $\begin{array}{l}273 \pm 4.0^{\mathrm{a}} \\
(\mathrm{n}=6)\end{array}$ & $\begin{array}{l}110 \pm 4.9^{b} \\
(\mathrm{n}=5)\end{array}$ & - & - & - & - \\
\hline LP control & $\begin{array}{l}378 \pm 4.9^{c} \\
(\mathrm{n}=23) \\
\end{array}$ & $\begin{array}{l}95 \pm 2.0^{\mathrm{a}} \\
(\mathrm{n}=12)\end{array}$ & $\begin{array}{l}15.0 \pm 0.45 \\
(n=10)\end{array}$ & $\begin{array}{l}2 / 150(1.3 \%) \\
(\mathrm{n}=10)\end{array}$ & $\begin{array}{l}2.23 \pm 0.04^{b} \\
(\mathrm{n}=10)\end{array}$ & $\begin{array}{l}0.39 \pm 0.04^{\mathrm{a}, \mathrm{b}} \\
(\mathrm{n}=10)\end{array}$ \\
\hline LP L-NAME & $\begin{array}{l}348 \pm 5.3^{\mathrm{b}, \mathrm{c}} \\
(\mathrm{n}=16)\end{array}$ & $\begin{array}{l}126 \pm 2.0^{c} \\
(\mathrm{n}=16)\end{array}$ & $\begin{array}{l}14.0 \pm 0.54 \\
(\mathrm{n}=15)\end{array}$ & $\begin{array}{l}11 / 210(5.2 \%) \\
(\mathrm{n}=15)\end{array}$ & $\begin{array}{l}1.96 \pm 0.05^{\mathrm{a}} \\
(\mathrm{n}=15)\end{array}$ & $\begin{array}{l}0.39 \pm 0.01^{\mathrm{a}} \\
(\mathrm{n}=15)\end{array}$ \\
\hline $\begin{array}{l}\text { LP L-NAME + } \\
\text { hydralazine }\end{array}$ & $\begin{array}{l}341 \pm 10.5^{\mathrm{b}, \mathrm{c}} \\
(\mathrm{n}=14)\end{array}$ & $\begin{array}{l}103 \pm 3.3^{b} \\
(\mathrm{n}=9)\end{array}$ & $\begin{array}{l}14.2 \pm 0.53 \\
(\mathrm{n}=14)\end{array}$ & $\begin{array}{l}9 / 199(4.5 \%) \\
(\mathrm{n}=14)\end{array}$ & $\begin{array}{l}2.11 \pm 0.10^{\mathrm{a}, \mathrm{b}} \\
(\mathrm{n}=14)\end{array}$ & $\begin{array}{l}0.44 \pm 0.01^{\mathrm{b}} \\
(\mathrm{n}=14)\end{array}$ \\
\hline
\end{tabular}

Values are expressed as mean \pm SEM, different letters denote statistical significance, $\mathrm{p}<0.05$.

${ }^{1}$ Mean arterial pressure from day 5 of the 10-day treatment (gestational day 14-15 for LP animals).

and raised to $200 \mathrm{~mm} \mathrm{Hg}$ in $20-\mathrm{mm} \mathrm{Hg}$ increments, for 5-20 min at each pressure, to determine myogenic tone as a function of transmural pressure.

At the end of the experiment, all vessels were subjected to 40 $\mathrm{mM} \mathrm{K}^{+}$PSS (made by substituting equimolar amounts of $\mathrm{KCl}$ for $\mathrm{NaCl}$ ) at $60 \mathrm{~mm} \mathrm{Hg}$ to ensure even constriction/vessel viability. After treatment with high $\mathrm{K}^{+}$, all vessels were fully relaxed with a solution containing $100 \mu \mathrm{M}$ papaverine and $10 \mu \mathrm{M}$ diltiazem, and subjected to the same pressure steps as above to obtain passive diameters. The tone (\%) seen at each pressure was calculated by: $\varnothing_{\mathrm{p}}-\varnothing_{\mathrm{a}} / \varnothing_{\mathrm{p}} \times 100$, where $\varnothing_{\mathrm{a}}$ is the active inner diameter at each pressure step and $\emptyset_{\mathrm{p}}$ is the corresponding passive inner diameter in the papaverine plus diltiazem solution. Both inner and outer arterial diameters were recorded at each pressure, and wall thickness derived by subtracting the inner diameter from the outer diameter and dividing by two.

\section{Remodeling Index}

The amount of expansive outward growth (increased lumen diameter) or inward remodeling (decreased lumen diameter) in each treatment group was calculated as the percentage change (positive or negative) from the average lumen diameter of agematched nonpregnant control vessels. All measurements were made at a transmural pressure of $80 \mathrm{~mm} \mathrm{Hg}$ and under fully relaxed conditions, as described above.

\section{Solutions}

PSS composition (in $\mathrm{mM}$ ): $119 \mathrm{mM} \mathrm{NaCl}, 4.7 \mathrm{mM} \mathrm{KCl}, 24.0$ $\mathrm{mM} \mathrm{NaHCO}_{3}, 1.2 \mathrm{mM} \mathrm{KH}_{2} \mathrm{PO}_{4}, 1.6 \mathrm{mM} \mathrm{CaCl}_{2}, 1.2 \mathrm{mM} \mathrm{MgSO}_{4}$, $0.023 \mathrm{mM}$ EDTA and $11.0 \mathrm{mM}$ glucose, $\mathrm{pH}=7.4$. Unless otherwise noted, all buffer reagents and chemicals were purchased from Sigma Chemical Co. (St. Louis, Mo., USA) or Fisher Scien- tific Co. (Pittsburgh, Pa., USA) and prepared on the day of an experiment.

\section{Statistical Analyses}

Statistical differences among all six treatment groups were determined from individual vessel data (SigmaPlot 9.0; Systat Software Inc., San Jose, Calif., USA) by analysis of variance to evaluate inter- and intragroup variability followed by multiple comparisons tests to stratify differences between treatment means. $p$ values of 0.05 or less were considered significant and are connoted by different letter superscripts. Data are expressed as mean values \pm standard error of the mean, with $n$ values representing the number of animals (one vessel used per animal). Regression analysis was performed, followed by the calculation of the coefficient of determination $\left(\mathrm{r}^{2}\right)$ to determine the relationship between blood pressure and percent tone.

\section{Results}

\section{Effects of L-NAME and Hydralazine Treatment on}

Maternal and Fetal Characteristics (table 1)

Maternal body weight was similar in all NP groups, though the animals in the NP-L and NP-L+H groups trended smaller than in NP-C. While LP controls were significantly heavier than the animals in all NP groups, both the LP-L and LP-L+H animals were smaller than LP controls. 


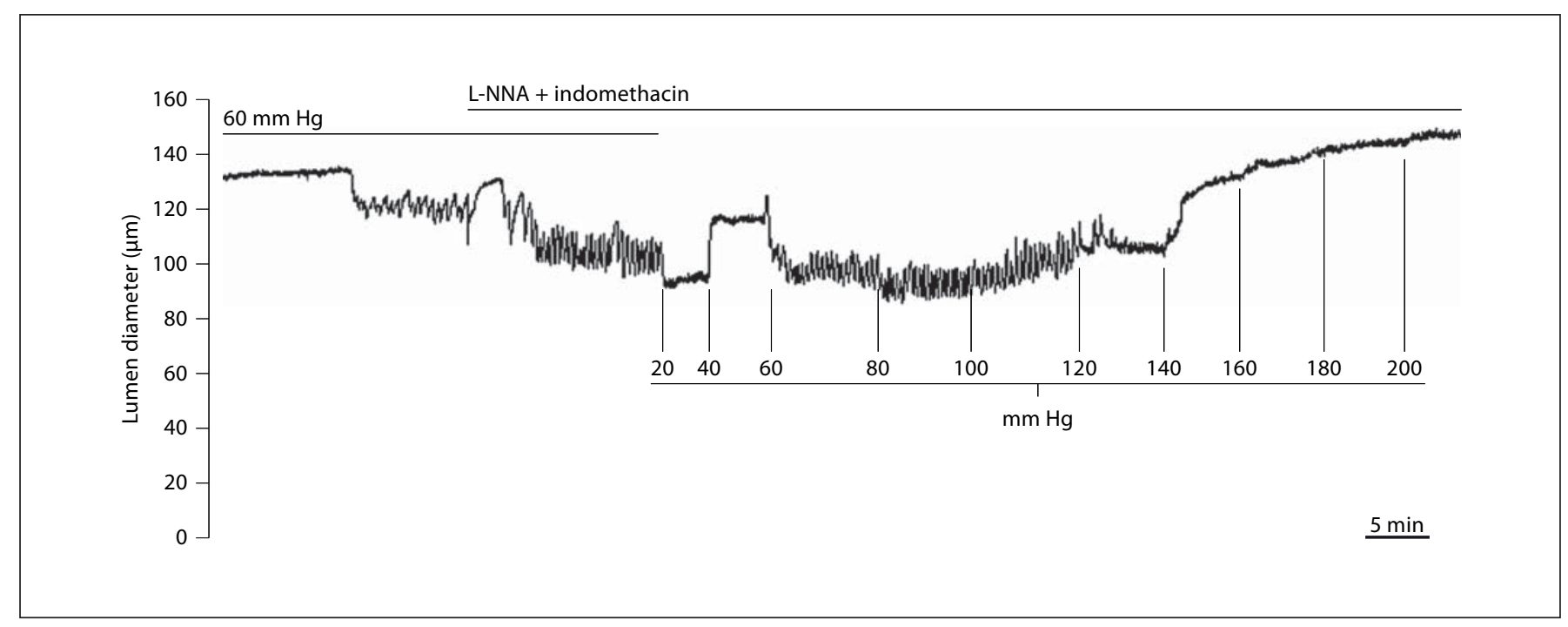

Fig. 1. Representative experimental tracing showing the relationship between transmural pressure and lumen diameter in a uterine radial artery from an LP-L+H animal. Note the development of tone during equilibration at $60 \mathrm{~mm} \mathrm{Hg}$, and additional constriction following the addition of $0.2 \mathrm{mM} \mathrm{L-NNA}+10 \mu \mathrm{M}$ indomethacin to inhibit endogenous $\mathrm{NO}$ and prostanoid production, respectively. Once tone developed, lowering pressure to $20 \mathrm{~mm}$ $\mathrm{Hg}$ induced an inhibition of constriction, with passive responses in diameter to elevations in pressure to $40 \mathrm{~mm} \mathrm{Hg}$. Tone redeveloped at $60 \mathrm{~mm} \mathrm{Hg}$, and was maintained up to $140 \mathrm{~mm} \mathrm{Hg}$, at which point forced dilatation occurred.
Mean arterial pressures at the midpoint of the 10-day treatment (in LP animals, day 14-15 of gestation) showed increases in both the NP-L versus NP-C group and the LP-L versus LP-C group ( $\mathrm{p}<0.05$ for both comparisons; table 1). In the NP-L+H animals, hydralazine treatment prevented the increase in blood pressure, while in the LP$\mathrm{L}+\mathrm{H}$ group, pressures were intermediate between those of LP-C and LP-L animals.

In terms of fetal parameters, litter sizes and resorption rates (determined by averaging the number of degenerated pups per litter) were comparable in all LP groups. While fetal weights were significantly reduced in LP-L compared to LP-C, fetal weights from LP-L+H animals were intermediate. Placental weights were similar in LP-C and LP-L, but somewhat heavier in animals cotreated with hydralazine $(\mathrm{p}<0.05 \mathrm{vs}$. L-NAME treatment alone).

\section{Pregnancy-Specific Myogenic Tone Differences due to} $L-N A M E$ and Hydralazine Treatment

To illustrate the behavior of an isolated myogenic vessel in response to changes in pressure, an experimental tracing from the $\mathrm{LP}-\mathrm{L}+\mathrm{H}$ group is shown in figure 1 . Tone developed during the $60-\mathrm{mm} \mathrm{Hg}$ equilibration and further constriction was seen with the addition of $0.2 \mathrm{mM} \mathrm{L-NNA}$ and $10 \mu \mathrm{M}$ indomethacin. The diameter stabilized and then increased progressively at 20 and $40 \mathrm{~mm} \mathrm{Hg}$ due to passive distension. Tone redeveloped at $60 \mathrm{~mm} \mathrm{Hg}$ and was maintained until $140 \mathrm{~mm} \mathrm{Hg}$, when forced dilatation occurred in response to step increases in pressure.

The level of myogenic tone at $80 \mathrm{~mm} \mathrm{Hg}$ in vessels from each treatment group is shown in figure 2a. For clarity of data presentation, $80 \mathrm{~mm} \mathrm{Hg}$ was chosen to represent a single pressure within the physiologic range likely experienced by these vessels in vivo. Arteries from NP-C animals had little or no tone at $80 \mathrm{~mm} \mathrm{Hg}(5 \pm$ $2.6 \%$ ), while those from the NP-L group had significantly more tone, $31 \pm 3.1 \%(\mathrm{p}<0.05)$. The average level of tone in vessels from the NP- $\mathrm{L}+\mathrm{H}$ group was similar to that of the NP-C group $(13 \pm 5.7 \%$ vs. $5 \pm 2.6 \%$; $p>0.05)$.

Late pregnant controls had $39 \pm 3.2 \%$ tone at $80 \mathrm{~mm}$ $\mathrm{Hg}$, while a significant reduction was seen in the LP-L group, with $11 \pm 5.0 \%$ tone $(\mathrm{p}<0.05)$. Co-treatment with hydralazine (LP-L+H group) prevented this attenuation, with $28 \pm 3.6 \%$ tone observed at $80 \mathrm{~mm} \mathrm{Hg}$, statistically the same as in late pregnant controls $(\mathrm{p}>0.05)$.

\section{Patterns of Arterial Remodeling}

To highlight the extent of remodeling in all groups compared to NP-C, a remodeling index is presented in 


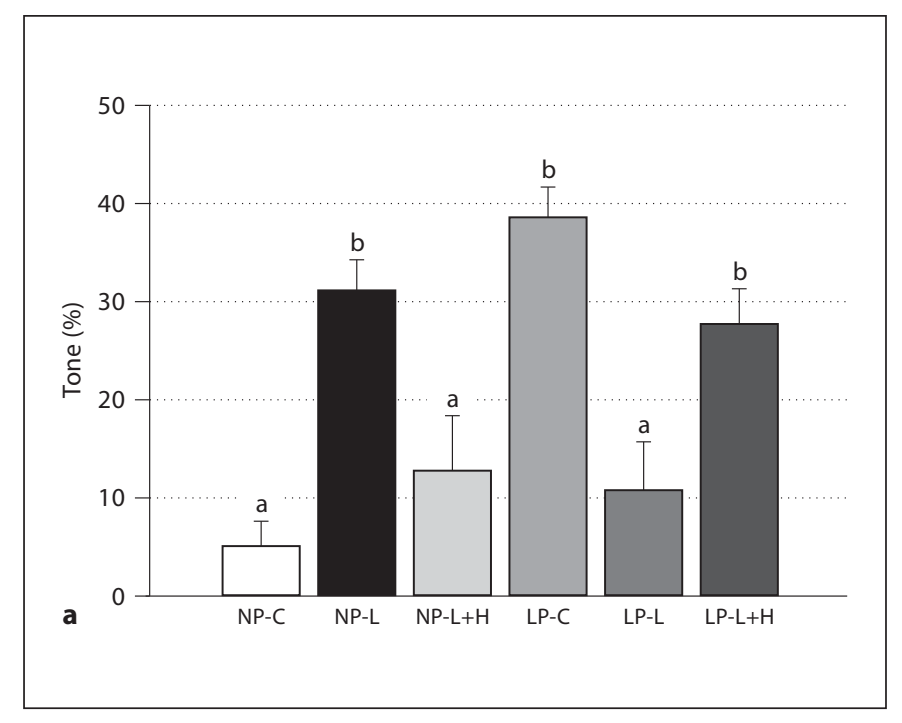

Fig. 2. a Myogenic tone (\%) in uterine radial vessels from all treatment groups at $80 \mathrm{~mm} \mathrm{Hg}$. The levels of tone in vessels from nonpregnant L-NAME (NP-L, $\mathrm{n}=7$ ), late pregnant control ( $\mathrm{LP}-\mathrm{C}$, $\mathrm{n}=6)$, and late pregnant L-NAME + hydralazine ( $\mathrm{LP}-\mathrm{L}+\mathrm{H}, \mathrm{n}=8)$ groups were statistically similar to each other, and different from nonpregnant control (NP-C, $\mathrm{n}=4$ ), nonpregnant L-NAME + hydralazine $(\mathrm{NP}-\mathrm{L}+\mathrm{H}, \mathrm{n}=6)$, and late pregnant L-NAME (LP-L, $\mathrm{n}=8$ ) animals (all of which were statistically similar to each other).

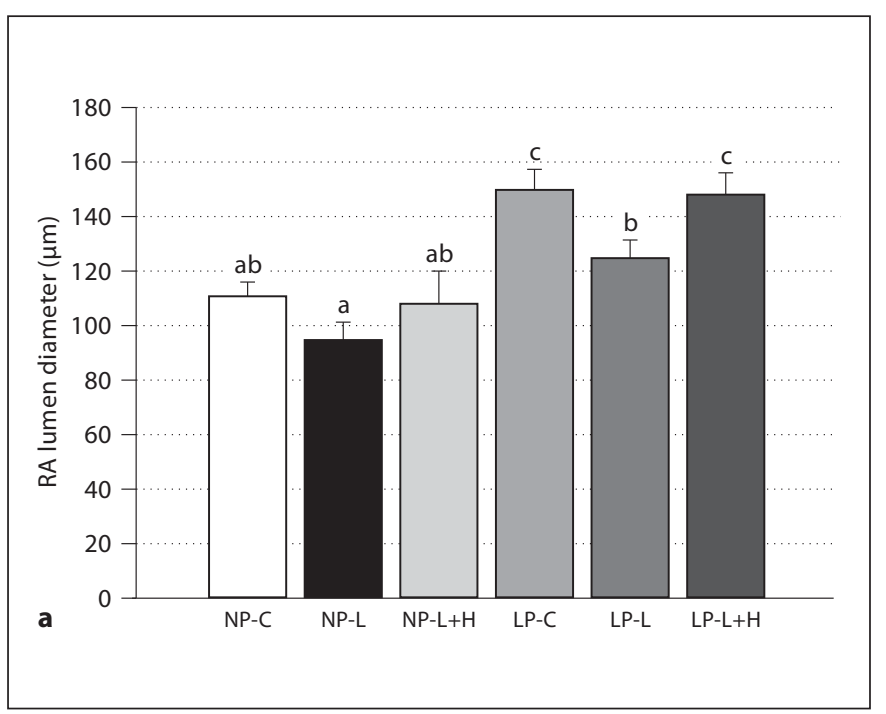

Fig. 3. a Passive lumen diameters (mean \pm SEM) of uterine radial arteries (RA) from all groups measured at $80 \mathrm{~mm} \mathrm{Hg}$ in a relaxing solution containing $100 \mu \mathrm{M}$ papaverine and $10 \mu \mathrm{M}$ diltiazem. Note the approximately $35 \%$ increase in lumen diameter in the LP-C vs. NP-C groups that is indicative of expansive remodeling. Different letters denote statistical significance $(\mathrm{p}<$

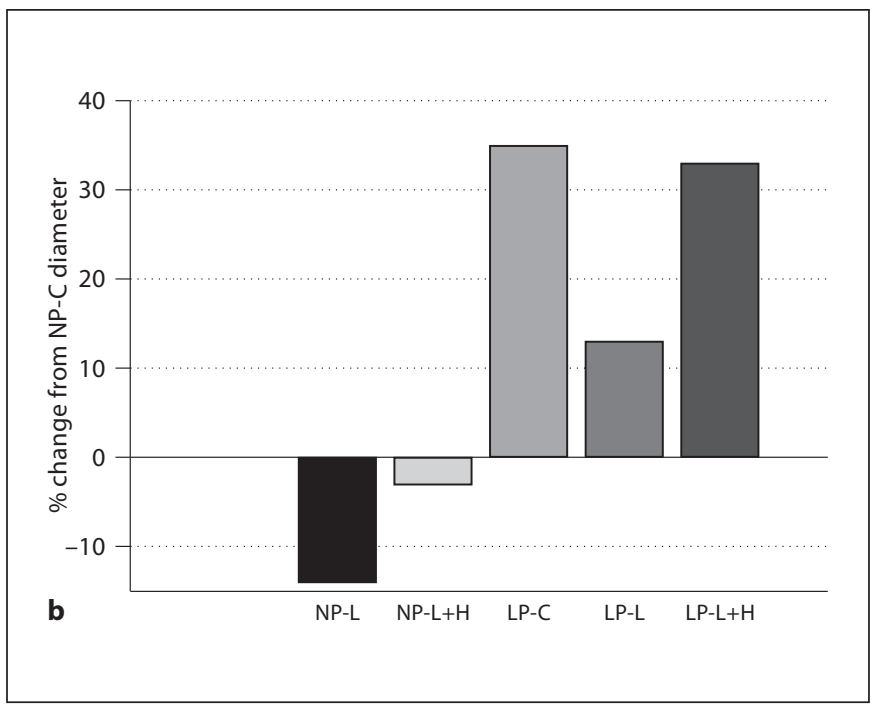

Different letters denote statistical significance, $\mathrm{p}<0.05$. Values presented as mean \pm SEM. b Remodeling index measured as percent change from NP-C $(n=12)$ lumen diameters at $80 \mathrm{~mm} \mathrm{Hg}$. NP-L $(n=10)$ and NP-L+H $(n=6)$ had negative indicies (reduction in lumen diameter), while LP-C $(\mathrm{n}=12)$, LP-L $(\mathrm{n}=15)$, and LP$\mathrm{L}+\mathrm{H}(\mathrm{n}=12)$ were positive. Note the correlation between percent tone (shown in a) and remodeling index in the pregnant groups, and the absence of this correlation in the nonpregnant groups.

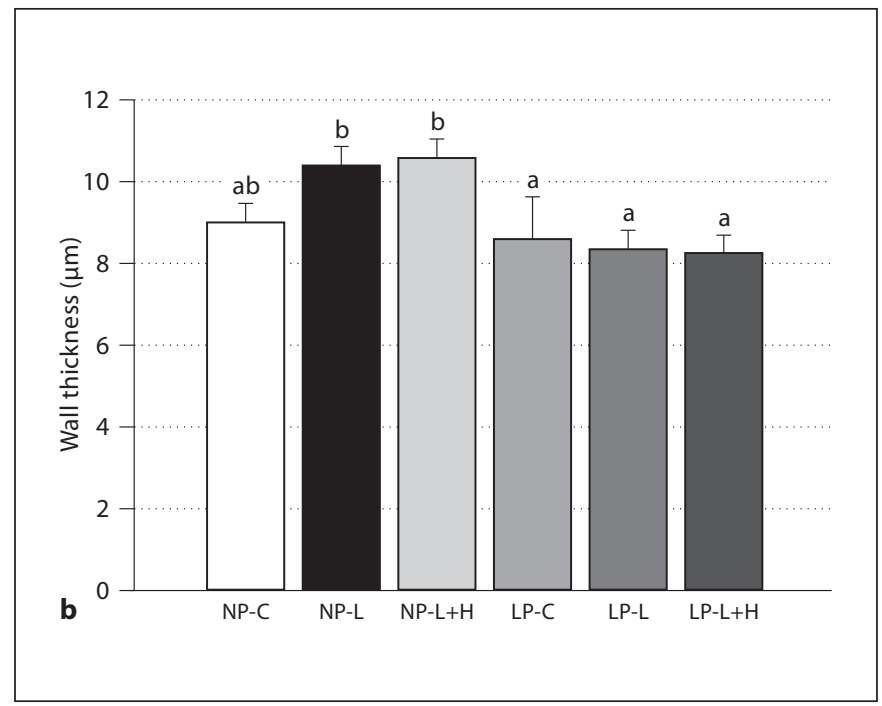

0.05 ); the same letter denotes statistical similarity ( $p \geq 0.05$ ). b Wall thickness of the same arteries as in a at $80 \mathrm{~mm} \mathrm{Hg}$. Values presented as mean \pm SEM. Different letters denote statistical significance $(\mathrm{p}<0.05)$; the same letter denotes statistical similarity $(\mathrm{p} \geq 0.05)$. For both $\mathbf{a}$ and $\mathbf{b}, \mathrm{n}$ values are: NP-C 12, NP-L 10, NP-L+H 6, LP-C 12, LP-L 15, LP-L+H 12. 


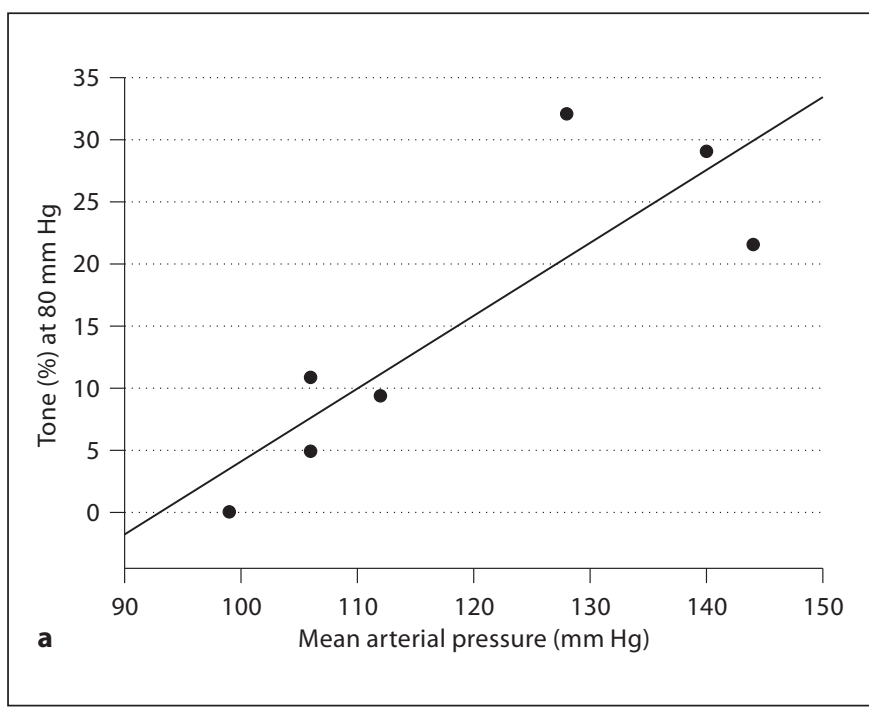

Fig. 4. a Positive correlation between mean arterial pressure (mm $\mathrm{Hg}$ ) and level of tone (\%) at $80 \mathrm{~mm} \mathrm{Hg}$ in vessels from all nonpregnant groups $\left(\mathrm{r}^{2}=0.74, \mathrm{p}=0.013\right)$. b Absence of correlation be-

figure 2b. Compared to NP-C vessel diameters at $80 \mathrm{~mm}$ $\mathrm{Hg}$, both NP-L and NP-L+H vessels had negative indices (smaller lumen diameters), of -14 and $-3 \%$, respectively. Vessels from LP control animals underwent significant expansive gestational remodeling, with a remodeling index of $35 \%$ greater than NP controls, while L-NAME treatment attenuated this process, resulting in a value of $13 \%$. Co-treatment with hydralazine and L-NAME reinstated the gestational remodeling, with a $33 \%$ remodeling index. Note the similar pattern between the level of tone (fig. 2a) and degree of remodeling (fig. 2b) in the late pregnant groups. Both LP-C and LP-L+LH had similar levels of tone and similar levels of gestational remodeling, while vessels from LP-L animals had attenuated remodeling and tone. This relationship was absent in the nonpregnant group, where the NP-L group had tone, yet lumen diameters were smaller than in NP-C.

To detail the structural changes in vessels due to treatment and pregnancy, lumen diameters and wall thicknesses are shown in figure 3 . As seen in figure 3a, passive lumen diameters at $80 \mathrm{~mm} \mathrm{Hg}$ (fully relaxed in a solution containing $100 \mu \mathrm{M}$ papaverine and $10 \mu \mathrm{M}$ diltiazem) were significantly larger in LP-C versus all NP groups and the LP-L group. All NP groups were similar and the $\mathrm{LP}-\mathrm{L}+\mathrm{H}$ group was statistically similar to LP-C $(\mathrm{p}>0.05)$. Figure $3 \mathrm{~b}$ shows decreases in wall thickness in the LP groups compared to the NP groups as well as increased

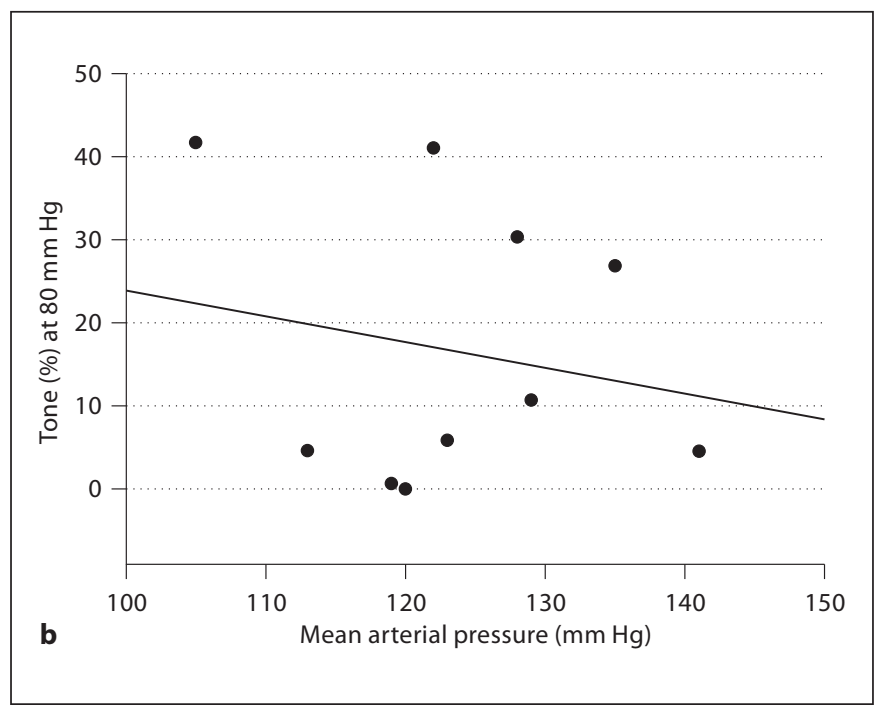

tween mean arterial pressure and tone (\%) at $80 \mathrm{~mm} \mathrm{Hg}$ in all late pregnant groups $\left(\mathrm{r}^{2}=0.04, \mathrm{p}>0.05\right)$.

wall thickness in the NP-L and NP-L+H groups compared to NP-C. These patterns were preserved across a wide range of transmural pressures.

\section{Regression Analyses}

In all NP animals, a strong positive correlation was noted between the level of arterial tone and mean arterial pressure; for example at $80 \mathrm{~mm} \mathrm{Hg}, \mathrm{r}^{2}=0.74$ (fig. $4 \mathrm{a}$ ), although this may be overestimated due to the somewhat bimodal distribution of the data. In vessels from LP animals (both control and treated), there was no correlation between mean arterial pressure and percent tone seen at $80 \mathrm{~mm} \mathrm{Hg}\left(\mathrm{r}^{2}=0.04\right.$; fig. 4b). Similar relationships were seen throughout the physiologic range of pressures (data not shown in the interest of simplicity).

\section{Discussion}

Myogenic tone is a fundamental property of small arteries and has been previously documented in the uterine circulation in pregnancy in both human and animal studies $[16,17,22-26]$. While the utility of myogenic tone in late pregnancy is not clear, in animals with hemochorial placentation like the human and rodent, tone likely serves to keep intervillous space pressure low within the placenta (thereby preventing compression of fetal villi), 
and secondarily acts as a possible mechanism for limiting bleeding during parturition and in the postpartum period.

In other circulations, myogenic tone has been documented as increased in hypertension [27-30]. In our study, this was the case with nonpregnant uterine vessels. However, in pregnancy, the pattern of tone development was closely connected to the pattern of gestational remodeling. Uterine radial vessels increase in diameter by approximately $35 \%$ in pregnancy, but this process was significantly attenuated in the late pregnant L-NAMEtreated animals, in which the lumen diameters were similar in size to nonpregnant controls. When late pregnant animals were treated with hydralazine in addition to LNAME (maintaining NO inhibition but lowering blood pressure), both expansive arterial remodeling and tone were reinstated. Interestingly, this correlation is not evident in the nonpregnant groups, where an increased amount of tone was seen in vessels from nonpregnant animals treated with L-NAME, yet a decrease in lumen diameter occurred. Together, these data implicate remodeling rather than hypertension as the dominant influence underlying the appearance of uterine artery myogenic tone in pregnancy.

Since hydralazine induces vascular smooth muscle (VSM) relaxation via multiple mechanisms [31-33], the pathways by which it affects remodeling and activation of tone are not known. Moreover, recent studies have demonstrated that hydralazine augments flow-induced remodeling through a mechanism linked to reactive oxygen species [34]. This observation invokes an additional, endothelial component, since an increase in intra-arterial shear stress due to the reduction in downstream resistance secondary to hemochorial placentation likely plays a role in maternal uterine vascular remodeling during gestation [11]. In other regional circulations, the mechanism underlying flow-induced remodeling has been shown to be endothelium-dependent in a number of earlier studies [35-37], although these observations have not been confirmed in the uterine circulation.

The most established mechanism for myogenicity is pressure/stretch-induced VSM membrane depolarization leading to calcium influx $[38,39]$; the activation of enzymes that increase calcium sensitivity (such as PKC, RhoA) is also recognized as an important complementary mechanism [40-44]. Accordingly, previous studies have shown an increase in VSM depolarization and cytosolic calcium in the uterine vasculature during myogenic tone development $[17,25]$. It is worth noting that the extent of tone in the uterine circulation has been shown to be dependent on vessel location - for example in the recent paper by Withers et al. [45] in which vessels taken immediately proximal to the uterine wall show little tone in the absence of prestimulation, and in our previous work [16], demonstrating the dependency of myogenic tone on both vessel type and location.

The gestational hypertrophy of VSM in uterine arteries [10] has also been documented to result in smooth muscle cell phenotypic changes $[17,46,47]$. This adaptive process, in combination with an increased wall tension and stress due to luminal enlargement without any thickening of the wall [11], may alter VSM cytoskeletal architecture and increase tensile forces at the level of the plasma membrane and thereby result in altered cellular signaling as well as contractility $[48,49]$. Thus, though wall tension and stress may also increase in the late pregnant L-NAME-treated group due to systemic hypertension, the absence of VSM phenotypic changes associated with gestational remodeling appears to preclude the development of tone.

Although myogenic tone can be augmented or reduced in pathophysiologic states such as hypertension [50] or sepsis [51,52], its presence is generally thought to be an inherent property of small resistance vessels. Notably, the appearance of tone during gestation in a vessel that is normally not myogenic in the nonpregnant state is quite an unusual phenomenon. Defining its basis from a mechanistic standpoint (for example altered expression or gating of calcium and potassium channels, as described in [17], or activation of calcium-sensitizing enzymes) would contribute to our understanding of myogenic behavior in general.

In summary, ours is the first study to link the development of myogenic tone to arterial remodeling, and to dissociate the roles of $\mathrm{NO}$ inhibition versus hypertension in this process. Future research should better elucidate the signals and pathways of VSM phenotypic adaptation during pregnancy, and further explore remodeling and tone as a function of gestational age and pre- and postpartum states.

\section{Acknowledgement}

This study was supported by NIH grant HL073895. 


\section{References}

1 Duvekot JJ, Peeters LL: Maternal cardiovascular hemodynamic adaptation to pregnancy. Obstet Gynecol Surv 1994;49:S1-S14.

-2 Podymow T, August P: Hypertension in pregnancy. Adv Chron Kidney Dis 2007;14: 178-190.

-3 Visser W, Wallenburg HC: Central hemodynamic observations in untreated preeclamptic patients. Hypertension 1991;17:10721077.

-4 Chang J, Elam-Evans LD, Berg CJ, Herndon J, Flowers L, Seed KA, Syverson CJ: Pregnancy-related mortality surveillance - United States, 1991-1999. MMWR Surveill Summ 2003;52:1-8.

5 Chesley LC: Hypertensive disorders in pregnancy. J Nurse Midwifery 1985;30:99-104.

-6 Harskamp RE, Zeeman GG: Preeclampsia: at risk for remote cardiovascular disease. Am J Med Sci 2007;334:291-295.

7 Wilson BJ, Watson MS, Prescott GJ, Sunderland S, Campbell DM, Hannaford P, Smith WC: Hypertensive diseases of pregnancy and risk of hypertension and stroke in later life: Results from cohort study. BMJ 2003; 326:845.

$\$ 8$ St-Louis J, Brochu M: The cardiovascular paradox of pregnancy. Med Sci (Paris) 2007; 23:944-949.

$\checkmark 9$ Uchida N, Mori A, Togo A, Ishiguro Y, Mikami M: Uteroplacental circulation, preeclampsia, and maternal abdominal aortic stiffness in normal and compromised pregnancies. J Perinat Med 2007;35:119-125.

10 Cipolla M, Osol G: Hypertrophic and hyperplastic effects of pregnancy on the rat uterine arterial wall. Am J Obstet Gynecol 1994;171: 805-811.

11 Osol G, Mandala M: Maternal uterine vascular remodeling during pregnancy. Physiology 2009;24:58-71.

-12 Khalil RA, Granger JP: Vascular mechanisms of increased arterial pressure in preeclampsia: lessons from animal models. Am J Physiol Regul Integr Comp Physiol 2002; 283:R29-R45.

13 Osol G, Barron C, Gokina N, Mandala M: Inhibition of nitric oxide synthases abrogates pregnancy-induced uterine vascular expansive remodeling. J Vasc Res 2009;46: 478-486.

14 Gilbert JS, Ryan MJ, LaMarca BB, Sedeek M, Murphy SR, Granger JP: Pathophysiology of hypertension during preeclampsia: linking placental ischemia with endothelial dysfunction. Am J Physiol 2008;294:H541H550.

15 Cipolla MJ, Binder ND, Osol G: Myoendometrial versus placental uterine arteries: Structural, mechanical, and functional differences in late-pregnant rabbits. Am J Obstet Gynecol 1997;177:215-221.
16 Gokina NI, Mandala M, Osol G: Induction of localized differences in rat uterine radial artery behavior and structure during gestation. Am J Obstet Gynecol 2003;189:14891493.

17 Telezhkin V, Goecks T, Bonev AD, Osol G, Gokina NI: Decreased function of voltagegated potassium channels contributes to augmented myogenic tone of uterine arteries in late pregnancy. Am J Physiol 2008; 294:H272-H284.

18 Duley L, Henderson-Smart DJ, Meher S: Drugs for treatment of very high blood pressure during pregnancy. Cochrane Database Syst Rev 2006;3:CD001449.

19 Magee LA, Cham C, Waterman EJ, Ohlsson A, von Dadelszen P: Hydralazine for treatment of severe hypertension in pregnancy: Meta-analysis. BMJ 2003;327:955-960.

20 Halpern W, Osol G: Blood vessel diameter measurement. Prog Appl Microcirc 1985;8: 32-39.

21 Halpern W, Osol G, Coy GS: Mechanical behavior of pressurized in vitro prearteriolar vessels determined with a video system. Ann Biomed Eng 1984;12:463-479.

22 Kublickiene KR, Cockell AP, Nisell H, Poston L: Role of nitric oxide in the regulation of vascular tone in pressurized and perfused resistance myometrial arteries from term pregnant women. Am J Obstet Gynecol 1997;177:1263-1269.

23 Kublickiene KR, Nisell H, Poston L, Kruger $\mathrm{K}$, Lindblom B: Modulation of vascular tone by nitric oxide and endothelin 1 in myometrial resistance arteries from pregnant women at term. Am J Obstet Gynecol 2000;182: 87-93.

24 Veerareddy S, Cooke CL, Baker PN, Davidge ST: Vascular adaptations to pregnancy in mice: effects on myogenic tone. Am J Physiol 2002;283:H2226-H2233.

25 Xiao D, Buchholz JN, Zhang L: Pregnancy attenuates uterine artery pressure-dependent vascular tone: role of PKC/ERK pathway. Am J Physiol 2006;290:H2337-H2343.

26 Osol G, Cipolla M: Interaction of myogenic and adrenergic mechanisms in isolated, pressurized uterine radial arteries from latepregnant and nonpregnant rats. Am J Obstet Gynecol 1993;168:697-705.

27 Ahn DS, Choi SK, Kim YH, Cho YE, Shin HM, Morgan KG, Lee YH: Enhanced stretchinduced myogenic tone in the basilar artery of spontaneously hypertensive rats. J Vasc Res 2007;44:182-191.

28 Cipolla MJ, DeLance N, Vitullo L: Pregnancy prevents hypertensive remodeling of cerebral arteries: a potential role in the development of eclampsia. Hypertension 2006;47: 619-626.
29 Vettoretti S, Ochodnicky P, Buikema H, Henning RH, Kluppel CA, de Zeeuw D, van Dokkum RP: Altered myogenic constriction and endothelium-derived hyperpolarizing factor-mediated relaxation in small mesenteric arteries of hypertensive subtotally nephrectomized rats. J Hypertens 2006;24: 2215-2223.

30 Falcone JC, Meininger GA: Endothelin mediates a component of the enhanced myogenic responsiveness of arterioles from hypertensive rats. Microcirculation 1999;6: 305-313.

-31 Knowles HJ, Tian YM, Mole DR, Harris AL: Novel mechanism of action for hydralazine: induction of hypoxia-inducible factor- $1 \alpha$, vascular endothelial growth factor, and angiogenesis by inhibition of prolyl hydroxylases. Circ Res 2004;95:162-169.

32 Liu C, Balanos GM, Fatemian M, Smith TG, Dorrington KL, Robbins PA: Effects of hydralazine on the pulmonary vasculature and respiratory control in humans. Exp Physiol 2008;93:104-114.

- 33 Vidrio H, Fernandez G, Medina M, Alvarez E, Orallo F: Effects of hydrazine derivatives on vascular smooth muscle contractility, blood pressure and cGMP production in rats: Comparison with hydralazine. Vasc Pharmacol 2003;40:13-21.

34 Dumont O, Pinaud F, Guihot AL, Baufreton C, Loufrani L, Henrion D: Alteration in flow (shear stress)-induced remodelling in rat resistance arteries with aging: Improvement by a treatment with hydralazine. Cardiovasc Res 2008;77:600-608.

- 35 Hull SS Jr, Kaiser L, Jaffe MD, Sparks HV Jr: Endothelium-dependent flow-induced dilation of canine femoral and saphenous arteries. Blood Vessels 1986;23:183-198.

-36 Langille BL, O’Donnell F: Reductions in arterial diameter produced by chronic decreases in blood flow are endothelium-dependent. Science 1986;231:405-407.

37 Rubanyi GM, Romero JC, Vanhoutte PM: Flow-induced release of endothelium-derived relaxing factor. Am J Physiol 1986; 250:H1145-H1149.

38 Schubert R, Mulvany MJ: The myogenic response: established facts and attractive hypotheses. Clin Sci (Lond) 1999;96:313-326.

39 Hill MA, Davis MJ, Meininger GA, Potocnik SJ, Murphy TV: Arteriolar myogenic signalling mechanisms: Implications for local vascular function. Clin Hemorheol Microcirc 2006;34:67-79.

40 Gokina NI, Knot HJ, Nelson MT, Osol G: Increased $\mathrm{Ca}^{2+}$ sensitivity as a key mechanism of PKC-induced constriction in pressurized cerebral arteries. Am J Physiol 1999; 277:H1178-H1188. 
-41 Laher I, Vorkapic P, Dowd AL, Bevan JA: Protein kinase $C$ potentiates stretch-induced cerebral artery tone by increasing intracellular sensitivity to $\mathrm{Ca}^{2+}$. Biochem Biophys Res Commun 1989;165:312-318.

42 Yeon DS, Kim JS, Ahn DS, Kwon SC, Kang BS, Morgan KG, Lee YH: Role of protein kinase $\mathrm{C}$ - or RhoA-induced $\mathrm{Ca}^{2+}$ sensitization in stretch-induced myogenic tone. Cardiovasc Res 2002;53:431-438.

43 Carter RW, Begaye M, Kanagy NL: Acute and chronic NOS inhibition enhances alpha(2)-adrenoreceptor-stimulated RhoA and Rho kinase in rat aorta. Am J Physiol 2002;283:H1361-H1369.

-44 Osol G: Mechanotransduction by vascular smooth muscle. J Vasc Res 1995;32:275-292.
45 Withers SB, Taggart MJ, Baker P, Austin C: Responses of isolated pressurised rat uterine arteries to changes in pressure: effects of preconstriction, endothelium and pregnancy. Placenta 2009;30:529-535.

46 Keyes LE, Moore LG, Walchak SJ, Dempsey EC: Pregnancy-stimulated growth of vascular smooth muscle cells: Importance of protein kinase C-dependent synergy between estrogen and platelet-derived growth factor J Cell Physiol 1996;166:22-32.

47 van der Heijden OW, Essers YP, Spaanderman ME, De Mey JG, van Eys GJ, Peeters LL: Uterine artery remodeling in pseudopregnancy is comparable to that in early pregnancy. Biol Reprod 2005;73:1289-1293.

48 Shaw A, Xu Q: Biomechanical stress-induced signaling in smooth muscle cells: an update. Curr Vasc Pharmacol 2003;1:41-58.

$\checkmark 49$ Shynlova OP, Oldenhof AD, Liu M, Langille L, Lye SJ: Regulation of c-fos expression by static stretch in rat myometrial smooth mus cle cells. Am J Obstet Gynecol 2002;186: 1358-1365.
50 Vicaut E: Hypertension and the microcirculation. Arch Mal Coeur Vaiss 2003;96:893903.

51 Snyder JG, Prewitt R, Campsen J, Britt LD: PDTC and Mg132, inhibitors of NF- $\kappa$, block endotoxin induced vasodilation of isolated rat skeletal muscle arterioles. Shock 2002;17:304-307.

52 Meziani F, Kremer H, Tesse A, Baron-Menguy C, Mathien C, Mostefai HA, Carusio N, Schneider F, Asfar P, Andriantsitohaina R: Human serum albumin improves arterial dysfunction during early resuscitation in mouse endotoxic model via reduced oxidative and nitrosative stresses. Am J Pathol 2007;171:1753-1761. 